(4) after adding hydrochloric acid, with potassium ferrocyanide. All the reagents used can be obtained free from metallic impurities.

As examples of the results obtained, calcium was reduced in sheep's liver (all tissues being dried on filter paper to remove oil) from $0 \cdot 10$ to 0.04 per cent ; copper from 0.05 to 0.035 per cent; and iron from 0.03 to less than 0.008 per cent. In sheep's spleen the calcium was reduced from 0.09 to 0.03 per cent and iron from 0.15 to 0.05 per cent, but the percentage of copper was slightly higher in the residue than in the dried spleen.

Further analysis by the flame method proves that precipitate (1) contains most of the copper, silver and some lead, (2) iron phosphate, (3) zinc and cadmium sulphides and (4) manganese, nickel, cobalt, cæsium (sometimes present) and some rubidium as ferrocyanides. Healthy liver contains much more zinc than appears to be realized; nickel was easily detected in it, but of cobalt there has only been the slightest evidence of its strongest line. The spleen and heart also contain zine and minute traces of nickel, and traces of cadmium were found in one sheep's liver and in a salmon's liver which also contained zinc and nickel. Arc or spark spectra of these precipitates would probably reveal the presence of other trace metals. The 'ashing' of tissues is often a very slow process, and some metals such as zinc, cadmium and the alkalis volatilize in varying degrees. These results are given tentatively as indications of the merits of the method and of the uses to which it may be applied.

Sheep diseases are very serious matters also in parts of Great Britain and are under investigation. Mr. J. B. E. Patterson, of Dartington Hall, Devon, recently sent me samples of the livers of four sheep which had died from one of these diseases, and evidence of changes in the mineral content as compared with normal livers has been obtained. There are indications too of a faulty metabolism resulting in the accumulation of oil, or compounds containing oil, in the liver to such an extent as to affect its normal working.

Many questions present themselves: for example, (1) effects of age on the composition of extract and residue; (2) changes caused by diseases, such as eancer; (3) changes due to imperfect feeding; (4) the effests of 'drugs', etc.; but the facilities at my command-a (spectroscopic) laboratory $14 \mathrm{ft}$. $\times$ $7 \mathrm{ft}$., furnished only with gas service-will not enable me to go far in answering them. This letter will serve, perhaps, to attract attention to what I believe to be a new and useful line of attack.

$$
\begin{aligned}
& 5 \text { Carrow Hill, } \\
& \text { Norwich. } \\
& \text { Oct. 12. } \\
& { }^{1} \text { NATURE, 137, } 67 \text { (1936). }
\end{aligned}
$$

\section{Relation of so-called Streptococcus apis to certain Lactic Acid Streptococci}

ONE of us has previously reported the isolation, from ıarvæ affected with European foul brood, of strains of Str, apis identical in every respect except that of gelatinolysis and caseolysis ${ }^{1}$. It has now been found that these two Str. apis strains are indistinguishable morphologically, culturally and biochemically from the well-recognized dairy types Str. glycerinaceus and Str. liquefaciens, the former being a non-proteolytic variant of the latter ${ }^{2,3}$. Thus all four types occur as diplococci and occasionally as short chains. They grow well in litmus milk at $15^{\circ}$ and at $45^{\circ}$ (the proteolytic Str. apis causing a breakdown of the casein similar to that produced by Str. liquefaciens); ferment glucose, fructose, lactose, galactose, maltose, mannose, sucrose and salacin strongly; glycerol, dextrin and trehalose slightly; but not arabinose, inulin, starch, xylose, inositol, adonitol or erythritol. Sorbitol and mannitol are usually, and raffinose not usually, fermented. Aesculin is fermented to give a positive reaction with ferric chloride. In glueose broth a final $p H$ of $4 \cdot 1-4 \cdot 2$ is obtained. All four types also grow in bile salt lactose broth, and resist heating at $60^{\circ}$ for 15 minutes in milk at $p \mathrm{H} 6 \cdot 6$.

The question of nomenclature and the relation of these types to other streptococci will be dealt with later.

\section{National Institute for \\ Research in Dairying, Shinfield.}

$$
\text { J. G. Davis. }
$$

Rothamsted Experimental Station, Harpenden.

'H. L. A. Tarr, Nature, 137, 151 (1936). Ann. Appl. Biol., 23, 558 (1936).

2 . Orla-Jensen, "The Lactic Acid Bacteria" (1919).

a. G. Davis, Proc. Soc. Agric. Buct. (1936).

\section{A New Microcolorimetric Apparatus and a Method} for Determination of Total Blood Volume

Ir is a matter of importance in physiology to construct an apparatus by which it is possible to determine the concentration of very weak dyesolutions in small quantities, without any decrease in its layer-thickness. In my apparatus a capillary tube is used with a volume of 10 cubic millimetres and a length of 20 millimetres. In this capillary tube is placed the dye-solution, the concentration of which is to be determined. The tube is covered with a black paper-hull to keep out the light from the side. The tube is hung vertically by a holder of simple construction on the object stage. This dye-solution is enlarged by the microscope, from which the eyepiece has been removed. In its place there is a prismsystem, which is similar to the upper part of a Duboscq colorimeter. The prism cuts off the rays in one half of the field of vision. Under the other half of this prism is fastened a wedge in order to compare the concentrations of the dye solutions. This wedge can be moved horizontally by a screw in front of a scale. Under the wedge is a light-filter, a diaphragm and an illuminating mirror from which the rays are directed through the filter, diaphragm and wedge to the other half of the eyepiece; the scale is determined by the aid of dye solutions of defined concentration. The unknown dye solution is put into the capillary tube. The wedge is screwed until there is an equalization of colour intensity and so the concentration of dye solution can be easily calculated. In this way one can estimate the colour concentration of dye solution between $1: 10,000$ $1: 100,000$. It can be used also for determination of weaker and stronger dye solutions by changing the length of the capillary tube.

This method was used for the estimation of the total blood volume of white rats. For the determina tion, Congo Red was used. The blood volume of forty 